\title{
Zanthoxylum schinifolium leaf ethanol extract inhibits adipocyte differentiation through inactivation of the extracellular signal regulated kinase and phosphoinositide 3-kinase/Akt signaling pathways in 3T3-L1 pre-adipocytes
}

\author{
EUN-OK CHOI ${ }^{1}$, CHEOL PARK $^{2}$, SOON SHIK SHIN ${ }^{3}$, EUN-JU CHO ${ }^{1}$, BYUNG WOO KIM $^{4,5}$, \\ JIN AH HWANG ${ }^{6}$, HYE-JIN HWANG ${ }^{5,7}$ and YUNG HYUN CHOI ${ }^{5,8}$
}

\begin{abstract}
${ }^{1}$ Department of Food and Nutrition, Busan National University, Busan $609-735 ;{ }^{2}$ Department of Molecular Biology, Dongeui University, Busan 614-714; ${ }^{3}$ Department of Formula Sciences, Dongeui University College of Korean Medicine, Busan 614-052; ${ }^{4}$ Department of Life Science and Biotechnology, ${ }^{5}$ Anti-Aging Research Center, Dongeui University, Busan 614-714;

${ }^{6}$ Department of Food and Nutrition, Myongji University, Yongin 449-728; ${ }^{7}$ Department of Food and Nutrition, Dongeui University, Busan 614-714; ${ }^{8}$ Department of Biochemistry, Dongeui University College of Korean Medicine, Busan 614-052, Republic of Korea
\end{abstract}

Received June 4, 2014; Accepted February 17, 2015

DOI: $10.3892 / \mathrm{mmr} .2015 .3463$

\begin{abstract}
Zanthoxylum schinifolium is widely used as a food flavoring in east Asia. Although this plant has also been used in traditional oriental medicine for the treatment of the common cold, toothache, stomach ache, diarrhea and jaundice, its anti-obesity activity remains to be elucidated. The present study investigated the effects of ethanol extract from the leaves of Z. schinifolium (EEZS) on adipocyte differentiation, and its underlying mechanism, in 3T3-L1 pre-adipocytes. The results demonstrated that EEZS effectively suppressed intracellular lipid accumulation at non-toxic concentrations, and was associated with the downregulation of several adipocyte-specific transcription factors, including peroxisome proliferation-activity receptor $\gamma$ (PPAR $\gamma)$, CCAAT/enhancer binding protein $(\mathrm{C} / \mathrm{EBP}) \alpha$ and $\mathrm{C} / \mathrm{EBP} \beta$, in a concentration-dependent manner. Furthermore, it was observed that EEZS markedly inactivated the extracellular signal-regulated protein kinase (ERK) and phosphatidylinositide 3-kinase (PI3K)/Akt pathways, which act upstream of PPAR $\gamma$ and $\mathrm{C} / \mathrm{EBPs}$ in adipogenesis. These results suggested that EEZS inhibited lipid accumulation by downregulating the major transcription factors involved in the pathway of adipogenesis, including PPAR $\gamma, \mathrm{C} / \mathrm{EBP} \alpha$ and $\mathrm{C} / \mathrm{EBP} \beta$, via regulation of the
\end{abstract}

Correspondence to: Professor Yung Hyun Choi, Department of Biochemistry, Dongeui University College of Korean Medicine, 52-57 Yangjeong-ro, Busanjin-gu, Busan 614-052, Republic of Korea E-mail: choiyh@deu.ac.kr

Key words: Zanthoxylum schinifolium, 3T3-L1 adipocyte, extracellular signal regulated kinase, Akt, peroxisome proliferator-activated receptor $\gamma, \mathrm{CAAT} / \mathrm{enhancer} \mathrm{binding} \mathrm{proteins}^{-}$
ERK and PI3K/Akt signaling pathways in 3T3-L1 adipocyte differentiation. This indicated the potential use of EEZS as an anti-obesity agent.

\section{Introduction}

Obesity is one of the most prevalent physiological disorders associated with a variety of conditions, including hypertension (1), dyslipidemia (2), atherosclerosis (3), type II diabetes (4), non-alcoholic fatty liver disease (5), periodontal disease (6), asthma (7), cardiovascular disease (8) and certain types of cancer $(9,10)$. Additionally, the number of obese individuals is continuing to increase and is becoming a serious health problem worldwide $(11,12)$. Therefore, there is a continuing requirement for novel and safe substances to overcome this problem, with a view to combating obesity-associated health problems (13).

Adipogenesis is regulated by a number of transcription factors, including the CCAAT/enhancer binding proteins (C/EBPs) and peroxisome proliferator-activated receptor $\gamma$ $(\mathrm{PPAR} \gamma)(14,15) . \mathrm{C} / \mathrm{EBP} \beta$ and $\mathrm{C} / \mathrm{EBP} \delta$ rapidly induce the expression levels of PPAR $\gamma$ and $\mathrm{C} / \mathrm{EBP} \alpha$. The PPAR $\gamma$ and $\mathrm{C} / \mathrm{EBP} \alpha$ proteins activate the expression of a number of genes involved in adipocyte differentiation, including genes responsible for lipid accumulation and insulin sensitivity (16). In addition, the activation of the extracellular signal regulated kinase (ERK) and phosphatidylinositide 3-kinase (PI3K)/Akt pathways is necessary for adipogenesis $(16,17)$. ERKs regulate cell proliferation and are required for initiating the differentiation process in pre-adipocytes. The phosphorylation of ERK is increased during the early stages of adipocyte differentiation in embryonic stem cells. Several previous studies have reported that inhibition of the ERK pathway in the early stages of differentiation inhibits adipogenesis, and there is increasing evidence demonstrating the importance of the ERK pathway in adipogenesis $(18,19)$. 
The involvement of Akt in adipocyte differentiation is better understood, and inhibition of the PI3K/Akt pathway has been demonstrated to reduce adipogenesis $(20,21)$.

Zanthoxylum schinifolium, which belongs to the Rutaceae family of plants, is an aromatic plant widely used as a pungent condiment and seasoning in Korea and other countries in east Asia (22). Z. schinifolium has also been used in traditional Chinese medicine for the treatment of several symptoms, including the common cold, diarrhea, toothache and jaundice. Additionally, various pharmacological activities, including the inhibition of lipid peroxidation (23), and anti-oxidant (24), antiplatelet aggregation (25), anti-inflammatory (26) and antitumor $(23,27,28)$ effects, have been reported by this plant. However, to the best of our knowledge, the potential anti-obesity activity of $Z$. schinifolium remains to be elucidated. Therefore, the aim of the present study was to determine the inhibitory ability of ethanol extract from the leaves of Z. schinifolium (EEZS) on adipocyte differentiation, using the 3T3-L1 murine pre-adipocyte model, determined by measuring the levels of lipid accumulation and the expression levels of adipocyte marker genes. The effects EEZS on the ERK and PI3K/Akt pathways were also examined to investigate the possible underlying molecular mechanisms.

\section{Materials and methods}

Preparation of EEZS. Z. schinifolium was obtained from Dongeui Oriental Hospital, Dongeui University College of Korean Medicine (Busan, Republic of Korea). Dried leaves from Z. schinifolium (40 g) were cut into small pieces, ground into a fine powder and then soaked with $500 \mathrm{ml} \mathrm{100 \%} \mathrm{ethanol}$ (Sigma-Aldrich, St. Louis, MO, USA) for 2 days. The extracted liquid was filtered through Whatman No. 3 filter paper (Sigma-Aldrich) twice to remove any insoluble materials and was then concentrated using a rotary evaporator (EYELA N-1000; Rikakikai Co., Ltd., Tokyo, Japan). The extracts were redissolved in dimethylsulfoxide (DMSO; Sigma-Aldrich) to a final concentration of $200 \mathrm{mg} / \mathrm{ml}$ (extract stock solution) and were subsequently diluted with Dulbecco's modified Eagle's medium (DMEM; WelGENE Daegu, Korea), to the desired concentration prior to use.

Cell culture and induction of adipocyte differentiation. The 3T3-L1 cell line was obtained from American Type Culture Collection (Manassas, VA, USA). The cells were cultured in DMEM, supplemented with $10 \%$ fetal bovine serum (FBS; WelGENE) and 1\% penicillin-streptomycin (Sigma-Aldrich) at $37^{\circ} \mathrm{C}$ in a humidified atmosphere of $5 \% \mathrm{CO}_{2}$. To initiate differentiation of the 3T3-L1 pre-adipocytes into adipocytes, the cells were stimulated with differentiation inducers, including 0.5 mM isobuthylmethylxanthine (Sigma-Aldrich), $10 \mu \mathrm{g} / \mathrm{ml}$ insulin (MDI; Sigma-Aldrich) and $1 \mu \mathrm{M}$ dexamethasone, which were added to the DMEM, containing 10\% FBS, for $48 \mathrm{~h}$. Following differentiation, the adipocytes were incubated with post-differentiation medium, which consisted of DMEM, containing 10\% FBS and $10 \mu \mathrm{g} / \mathrm{ml}$ insulin. The medium was replaced every other day for up to 8 days (29).

Cell viability. To assess the cell viability in the 3T3-L2 adipocytes, the cells were plated into 24 -well plates $\left(1 \times 10^{5}\right.$ cells $\left./ \mathrm{ml}\right)$ and incubated for $24 \mathrm{~h}$ at $37^{\circ} \mathrm{C}$ until confluent. The cells were subsequently treated with the indicated concentrations $(100-600 \mu \mathrm{g} / \mathrm{ml})$ of EEZS for $72 \mathrm{~h}$ at $37^{\circ} \mathrm{C}$. The control cells were supplemented with complete medium, containing $0.5 \%$ DMSO, as a vehicle control. Subsequent to incubation for $72 \mathrm{~h}$ at $37^{\circ} \mathrm{C}$, the medium was removed and the cells were incubated with $0.5 \mathrm{mg} / \mathrm{ml} \mathrm{3-(4,5-dimethylthiazol-2-yl)-2,5-di-}$ phenyltetrazolium bromide (MTT; Sigma-Aldrich) solution for $3 \mathrm{~h}$ at room temperature. The supernatant was subsequently discarded and the formazan blue, which had formed in the cells, was then dissolved in 100\% DMSO. The DMSO concentration did not exceed $0.05 \%$. The optical density was measured at $540 \mathrm{~nm}$ using a microplate reader (Dynatech Laboratories, Chantilly VA, USA) and the effects of EEZS on the inhibition of cell growth were assessed as the percentage of cell viability, in which the vehicle-treated cells were considered to be $100 \%$ viable.

Oil Red-O staining. The intercellular lipid accumulation within adipocytes was assessed using Oil Red-O solution. Following the induction of adipocyte differentiation, the cells were washed twice with phosphate-buffered saline (PBS; WelGENE) and fixed at room temperature with $10 \%$ formalin (Junsei Chemical Co., Ltd., Tokyo, Japan) for $1 \mathrm{~h}$. The cells were dried and stained with Oil Red-O $(0.35 \%$ Oil Red-O in $100 \%$ aqueous 2-isopropanol; Sigma-Aldrich) for $20 \mathrm{~min}$ at room temperature. Following staining of the lipid droplets, the Oil Red-O staining solution was removed, the plates were rinsed twice with PBS and 60\% isopropanol and were then dried. Images of the stained oil droplets in the 3T3-L1 cells were captured under light microscopy. To quantify the intracellular lipids, the stained lipid droplets were dissolved in isopropanol, containing 4\% Nonidet P-40 (NP-40; Sigma-Aldrich). The extracted dye was transferred into a 96-well plate, and the absorbance was measured using a microplate reader (MR5000; Dynatech Laboratories, Chantilly, VA, USA) at $500 \mathrm{~nm}$. The difference in absorbance between the samples with and without dye solution was calculated (30).

Protein extraction and western blot analysis. The cells were harvested and washed once with ice-cold PBS, and were gently lysed for $20 \mathrm{~min}$ in ice-cold lysis buffer containing $40 \mathrm{mM}$ Tris ( $\mathrm{pH} 8.0$ ), $120 \mathrm{mM} \mathrm{NaCl}, 0.5 \% \mathrm{NP}-40$, $0.1 \mathrm{mM}$ sodium orthovanadate, $2 \mu \mathrm{g} / \mathrm{ml}$ leupeptin and $100 \mu \mathrm{g} / \mathrm{ml}$ phenylmethylsulfonyl fluoride (all Sigma-Aldrich). The supernatants were collected and the protein concentrations were determined using a Bio-Rad protein assay kit (Bio-Rad Laboratories, Inc., Hercules, CA, USA). Equal quantities of the protein extracts were denatured by boiling at $95^{\circ} \mathrm{C}$ for $5 \mathrm{~min}$ in sample buffer (Bio-Rad Laboratories, Inc.), containing $0.5 \mathrm{M}$ Tris- $\mathrm{HCl}$ ( $\mathrm{pH} 6.8), 4 \%$ sodium dodecyl sulphate (SDS), $20 \%$ glycerol, $0.1 \%$ bromophenol blue and $10 \% \beta$-mercaptoethanol, at a ratio of $1: 1$. The samples were either stored at $-80^{\circ} \mathrm{C}$ or were used immediately for immunoblotting. Aliquots, containing $30 \mu \mathrm{g}$ total protein, were separated on $10 \%$ SDS-polyacrylamide gels and transferred onto nitrocellulose membranes (Amersham Life Sciences, Arlington Heights, IL, USA). The membranes were subsequently blocked with 5\% non-fat milk and incubated overnight at $4^{\circ} \mathrm{C}$ with primary antibodies, probed with enzyme-linked 
Table I. List of primary antibodies.

\begin{tabular}{llcl}
\hline Antibody & Dilution & Catalog no. & Species of origin and supplier \\
\hline C/EBP $\alpha$ & $1: 1,000$ & $2295 \mathrm{~s}$ & Rabbit polyclonal; Cell Signaling Technology, Inc. \\
C/EBP $\beta$ & $1: 1,000$ & $3087 \mathrm{~s}$ & Rabbit polyclonal; Cell Signaling Technology, Inc. \\
PPAR $\gamma$ & $1: 1,000$ & $2430 \mathrm{~s}$ & Rabbit polyclonal; Cell Signaling Technology, Inc. \\
ERK & $1: 1,000$ & $\mathrm{sc}-154$ & Rabbit polyclonal; Santa Cruz Biotechnology, Inc. \\
p-ERK & $1: 500$ & $9106 \mathrm{~S}$ & Mouse monoclonal; Cell Signaling Technology, Inc. \\
PI3K & $1: 1,000$ & $\mathrm{sc}-7176$ & Rabbit polyclonal; Santa Cruz Biotechnology, Inc. \\
p-PI3K & $1: 500$ & $\mathrm{sc}-293115$ & Rabbit polyclonal; Santa Cruz Biotechnology, Inc. \\
Akt & $1: 500$ & $\mathrm{sc}-8312$ & Rabbit polyclonal; Santa Cruz Biotechnology, Inc. \\
p-Akt & $1: 500$ & $\mathrm{sc}-161629$ & Rabbit polyclonal; Santa Cruz Biotechnology, Inc. \\
$\beta$-actin & $1: 1,000$ & Goat polyclonal; Santa Cruz Biotechnology, Inc.
\end{tabular}

CEBP, CCAAT/enhancer binding protein; PPAR $\gamma$, peroxisome peroxisome proliferator-activated receptor $\gamma$; ERK, extracellular signal-regulated protein kinase; p, phosphorylated; PI3K, phosphatidylinositide 3-kinase. Santa Cruz Biotechnology, Inc., Santa Cruz, CA, USA; Cell Signaling Technology, Inc., Danvers, MA, USA.

secondary antibodies at room temperature for a further $1 \mathrm{~h}$ and then detected using an enhanced chemiluminescence detection system (Amersham Life Sciences), according to the manufacturer's instructions. The primary antibodies were purchased from Santa Cruz Biotechnology, Inc. (Santa Cruz, CA, USA) and Cell Signaling Technology, Inc. (Danvers, MA, USA) (Table I). The horseradish peroxidase-conjugated anti-rabbit immunoglobulin G (IgG, sc-2004; 1:1,000), anti-mouse IgG (sc-2005; 1:1,500) and anti-goat IgG (sc-2350; 1:1,500) were purchased from Santa Cruz Biotechnology, Inc. $\beta$-actin was used as an internal control.

Statistical analysis. The data are expressed as the mean \pm standard deviation. Comparisons between the groups were made using analysis of variance and the significance between differences were analyzed using Duncan's multiple range test. Statistical analyses were performed using SPSS version 18.0 (SPSS Inc., Chicago, IL, USA). $\mathrm{P}<0.05$ was considered to indicate a statistical significant difference.

\section{Results}

Cytotoxic effects of EEZS on 3T3-L1 cells. To determine the cytotoxicity of EEZS, the 3T3-L1 cells were treated with various concentrations of EEZS and the cell viability was assessed using an MTT assay. The data demonstrated that EEZS exhibited no cytotoxic effects at concentrations $\leq 200 \mu \mathrm{g} / \mathrm{ml}$ (Fig. 1). Therefore, concentrations of 50, 100, 150 and $200 \mu \mathrm{g} / \mathrm{ml}$ were selected for use in the subsequent experiments.

EEZS inhibits adipogenesis in 3T3-L1 cells. As increased lipid accumulation during the differentiation of pre-adipocytes into adipocytes is a typical phenomenon, which occurs in 3T3-L1 cells and is used as a marker of differentiation, the 3T3-L1 pre-adipocytes were treated with various concentrations of EEZS in the presence of MDI or with MDI alone for 8 days. Lipid accumulation was subsequently measured in the cells using Oil Red-O staining. As shown in Fig. 2, oil

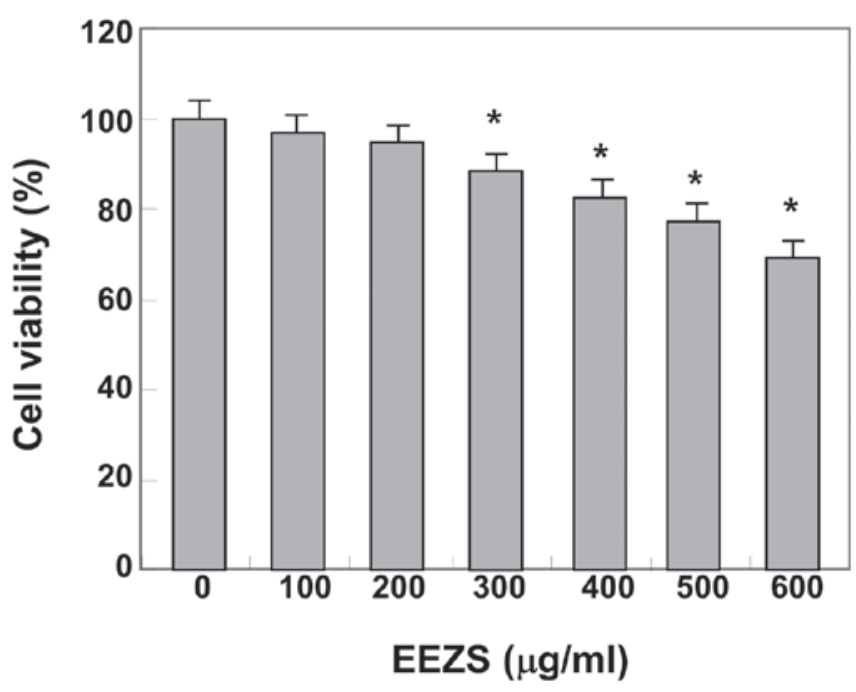

Figure 1. Effects of EEZS on the cell viability of 3T3-L1 mouse pre-adipocytes. The 3T3-L1 cells were cultured with various concentrations of EEZS for $72 \mathrm{~h}$ and the cell viability was measured using an MTT assay. The data are expressed as the mean \pm standard deviation of three independent experiments. The significance was determined using Student's t-test $\left({ }^{*} \mathrm{P}<0.05\right.$, vs. untreated control). EEZS, ethanol extract of leaves from Zanthoxylum schinifolium; MTT, 3-(4,5-dimethylthiazol-2-yl)-2,5-diphenyltetrazolium bromide.

droplets were not visible in the undifferentiated 3T3-L1 cells, however, several lipid droplets were visible in the fully differentiated cells treated with MDI. Microscopic observations of the Oil Red-O staining revealed a reduction in the number of lipid droplets as the concentrations of EEZS increased. The inhibitory effects of EEZS on the triglyceride contents of the differentiated adipocytes were measured, which revealed that the triglyceride contents of the adipocytes increased markedly during 8 days incubation with MDI (Fig. 3). However, treatment with EEZS decreased the triglyceride levels significantly, in a concentration-dependent manner. These results demonstrated that EEZS inhibited adipocyte differentiation in the 3T3-L1 cells at non-cytotoxic concentrations. 


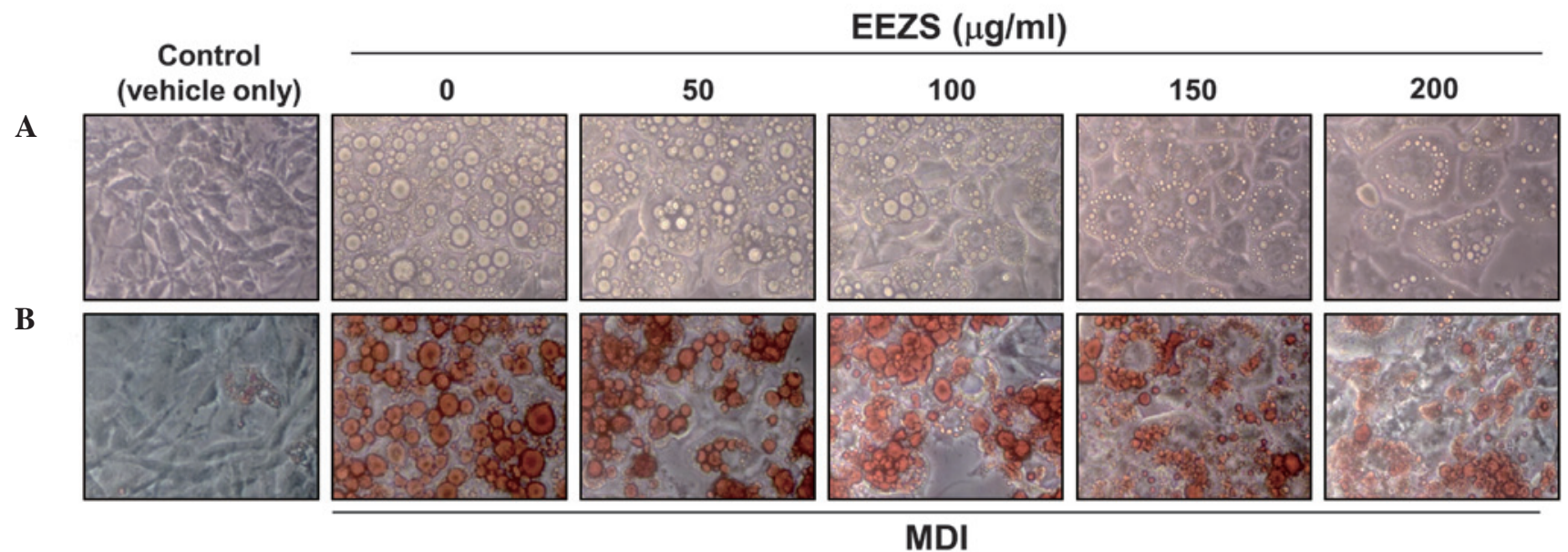

Figure 2. Effects of EEZS on triglyceride accumulation in differentiated 3T3-L1 cells. (A) Differentiation of confluent 3T3-L1 cells was initiated using MDI and maintained in Dulbecco's modified Eagle's medium, containing 10\% fetal bovine serum in the absence or presence of different concentrations of EEZS. Following culture for 8 days, the 3T3-L1 cells were examined by light microscopy (magnification, x200) and were (B) fixed and stained with Oil Red-O to visualize the lipid droplets by light microscopy (magnification, x200). EEZS, ethanol extract of leaves from Zanthoxylum schinifolium; MDI, insulin.

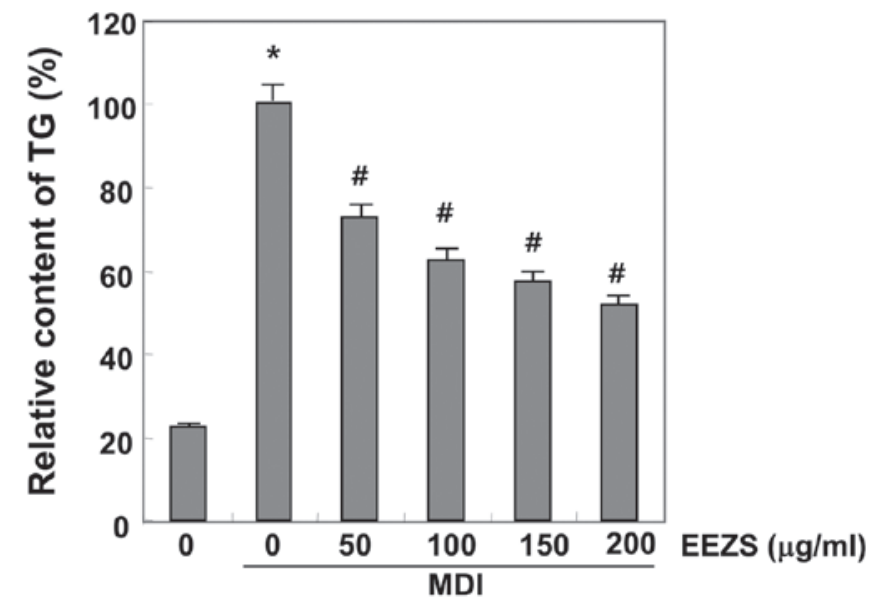

Figure 3. Effects of EEZS on triglyceride accumulation in differentiated 3T3-L1 cells. The triglyceride contents of the 3T3-L1 cells were determined by Oil Red-O staining following treatment in the absence or presence of different concentrations of EEZS. Subsequent to dissolving the triglyceride in isopropanol, the triglyceride contents were measured at $500 \mathrm{~nm}$ using a microplate reader. The data are expressed as the mean \pm standard deviation of three independent experiments. The significance was determined using Student's t-test ( ${ }^{*} \mathrm{P}<0.05$, vs. undifferentiated control; ${ }^{*} \mathrm{P}<0.05$, vs. differentiated control). EEZS, ethanol extract of leaves from Zanthoxylum schinifolium; MDI, insulin.

EEZS inhibits the expression of adipogenic transcription factors during adipocyte differentiation in 3T3-L1 cells. Adipogenesis is accompanied by the increased expression of adipogenic transcription factors and adipocyte-specific genes. To investigate the anti-adipogenic mechanism underlying EEZS, the fully differentiated adipocytes were treated with different concentrations of EEZS, and the protein expression levels of PPAR $\gamma, \mathrm{C} / \mathrm{EBP} \alpha$ and $\mathrm{C} / \mathrm{EBP} \beta$ were determined by western blot analysis. As expected, the levels of these three proteins were significantly upregulated during the process of differentiation (Fig. 4). However, treatment with EEZS suppressed the expression levels of $\operatorname{PPAR} \gamma, \mathrm{C} / \mathrm{EBP} \alpha$ and $\mathrm{C} / \mathrm{EBP} \beta$ compared with the fully differentiated control adipocytes, and this occurred in a concentration-dependent manner. This result suggested that EEZS inhibited adipogenesis by

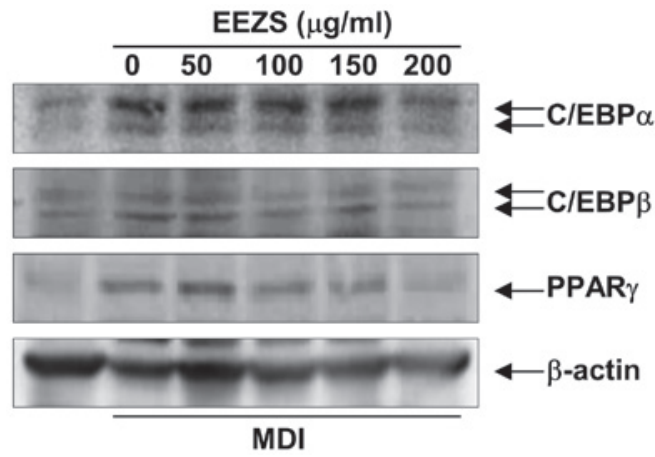

Figure 4. Effects of EEZS on the protein expression levels of adipogenic transcription factors in differentiated 3T3-L1 cells. The post-confluent 3T3-L1 cells were differentiated in the absence or presence of different concentrations of EEZS for 8 days following initiation with MDI. The cells were lysed and the cellular proteins were separated on sodium dodecyl sulphate-polyacrylamide gels and transferred onto nitrocellulose membranes. The membranes were probed with the indicated antibodies, and the proteins were visualized using an enhanced chemiluminescence detection system. $\beta$-actin was used as an internal control. EEZS, ethanol extract of leaves from Zanthoxylum schinifolium; MDI, insulin; PPAR, peroxisome proliferator-activated protein; C/EPB, CAAT/enhancer binding protein.

reducing the expression of $\mathrm{C} / \mathrm{EBP} \beta$, which lead to a downregulation in the expression levels of $\mathrm{C} / \mathrm{EBP} \alpha$ and $\mathrm{PPAR} \gamma$.

Anti-adipogenic effects of EEZS are associated with inactivation of the ERK and PI3K/Akt pathways in 3T3-L1 cells. The control of adipogenesis requires two well-established signaling mechanisms, the ERK and PI3K/Akt pathways, which are important upstream of adipocyte differentiation (17). The 3T3-L1 cells were pretreated with either ERK- or PI3K-specific inhibitors for $1 \mathrm{~h}$ prior to incubation with MDI in the presence or absence of $200 \mu \mathrm{g} / \mathrm{ml} \mathrm{EEZS,} \mathrm{and} \mathrm{the} \mathrm{levels}$ of phosphorylated-ERK, PI3K and Akt were determined at various time-points by western blotting. Consistent with previous data $(16,18)$, the expression of phosphorylated-ERK was significantly increased during the early stages of adipogenesis, and the activation continued for $3 \mathrm{~h}$ following the induction of adipocyte differentiation by DMI (Fig. 5A). 
A

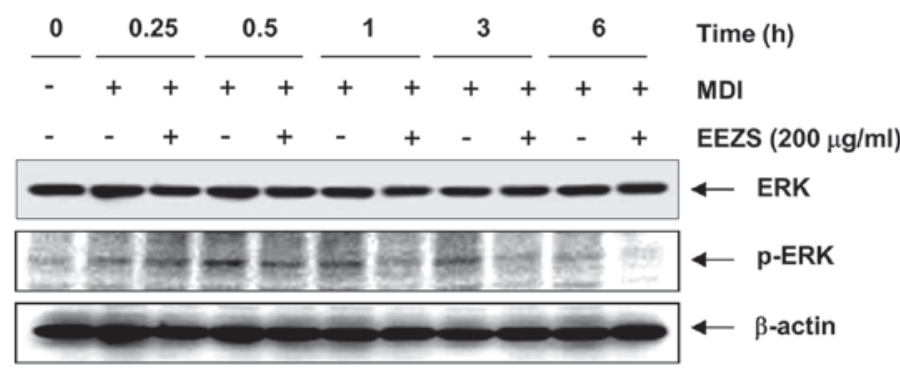

B

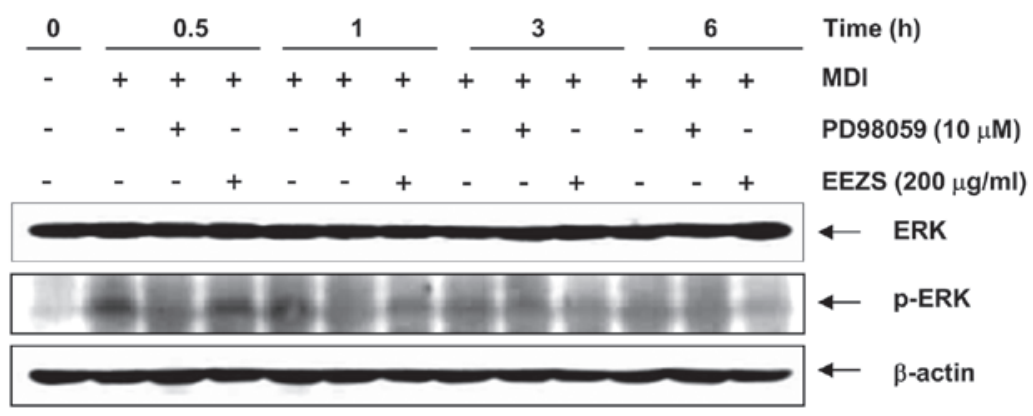

Figure 5. Effects of EEZS on the phosophorylation of ERK during the early stages of 3T3-L1 cell differentiation. (A) 3T3-L1 cells were either treated with MDI in the presence or absence of $200 \mu \mathrm{g} / \mathrm{ml}$ EEZS or were (B) pre-treated with $10 \mu \mathrm{M}$ PD98059 for $1 \mathrm{~h}$ prior to incubation with MDI in the presence or absence of $200 \mu \mathrm{g} / \mathrm{ml}$ EEZS. The cells were harvested at the indicated time-points and equal quantities of cell lysate were resolved on sodium dodecyl sulphate-polyacrylamide gels, transferred onto nitrocellulose membranes and probed with anti-ERK and anti-p-ERK antibodies. The proteins were visualized using an enhanced chemiluminescence detection system. $\beta$-actin was used as an internal control. EEZS, ethanol extract of leaves from Zanthoxylum schinifolium; MDI, insulin; ERK, extracellular signal regulated kinase; p-, phosphorylated.

A

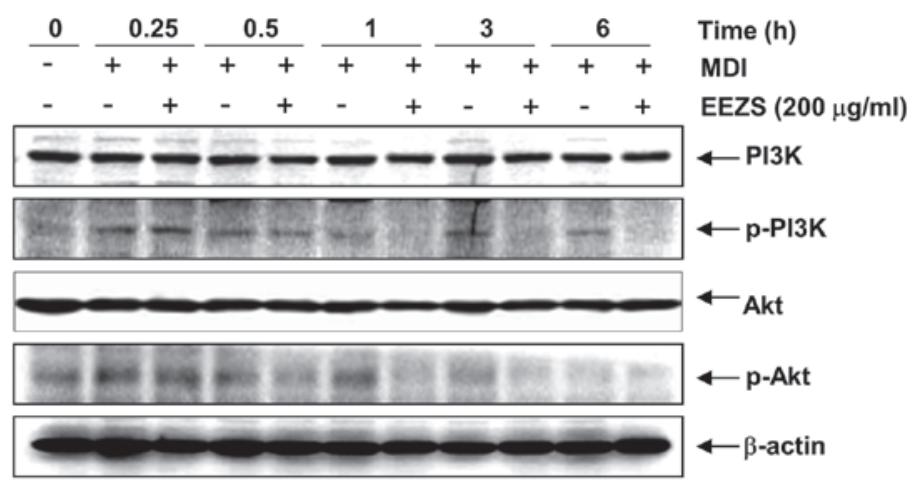

B

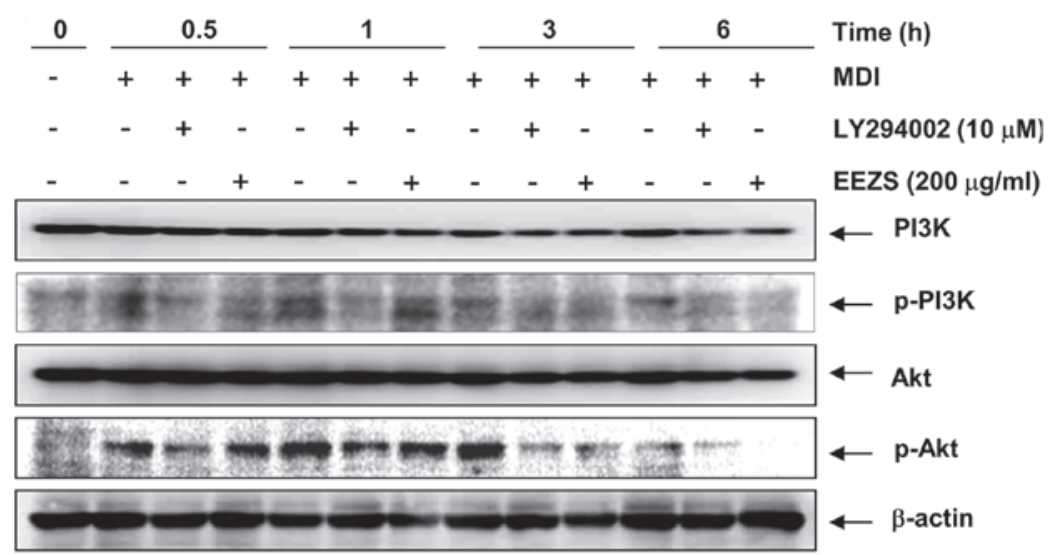

Figure 6. Effects of EEZS on the phosphorylation of PI3K and AKT during the early stages of 3T3-L1 cell differentiation. The 3T3-L1 cells were either treated with MDI in the presence or absence of (A) $200 \mu \mathrm{g} / \mathrm{ml}$ EEZS or were (B) pre-treated with $10 \mu \mathrm{M} \mathrm{LY} 294002$ for $1 \mathrm{~h}$ prior to incubation with MDI in the presence or absence of $200 \mu \mathrm{g} / \mathrm{ml}$ EEZS. The cells were harvested at the indicated time-points and equal quantities of the cell lysate were resolved on sodium dodecyl sulphate-polyacrylamide gels, transferred onto nitrocellulose membranes and were probed with the anti-PI3K, anti-p-PI3K, anti-Akt and anti-p-Akt antibodies. The proteins were visualized using an enhanced chemiluminescence detection system. $\beta$-actin was used as an internal control. EEZS, ethanol extract of leaves from Zanthoxylum schinifolium; MDI, insulin; p-, phosphorylated; PI3K, phosphoinositide 3-kinase. 
However, treatment with EEZS effectively suppressed the MDI-induced phosphorylation of ERK. The specific ERK inhibitor, PD98059, induced significant inhibition of the phosphorylation of ERK and used as a positive control for treatment with EEZS (Fig. 5B). As shown in Fig. 6, treatment with DMI rapidly induced the phosphorylation of $\mathrm{PI} 3 \mathrm{~K}$ and Akt, and this continued for $6 \mathrm{~h}$ subsequent to treatment. However, the levels of phosphorylated-PI3K and Akt were markedly attenuated following treatment with EEZS, similar to the results, which were obtained using LY294002, a PI3K-specific inhibitor. These results suggested that the inhibition of adipocyte differentiation by EEZS was associated with inactivation of the ERK and PI3K/Akt signaling pathways.

\section{Discussion}

Increased consumption of high calorie foods containing sugars and fats, and lack of physical activity lead to obesity, which is a major risk factor for serious chronic diseases, including diabetes, cardiovascular disease and hypertension (1-11). Adipocyte differentiation is an adaptive response to excess energy intake, inducing obesity and metabolic diseases (17,31). Accordingly, adipocytes are a therapeutic target in treatmenting obesity and investigations are being performed to prevent obesity through regulating adipogenesis. During adipogenesis, undifferentiated fibroblast-like pre-adipocytes become spherical fat cells and accumulate as lipid droplets $(32,33)$. The present study, as part of an ongoing investigation to identify anti-obesity agents from traditional medicine sources, investigated whether EEZS possessed anti-obesity activity using a 3T3-L1 pre-adipocyte model.

To investigate suppressive effects of EEZS on adipocyte differentiation, the effects of EEZS on the accumulation of intracellular lipids were determined using Oil Red-O staining and triglyceride content analysis in 3T3-L1 pre-adipocytes. The data demonstrated that EEZS significantly inhibited adipocyte differentiation and lipid accumulation in a concentration-dependent manner (Figs. 2 and 3). The concentrations of EEZS used to inhibit adipocyte differentiation exhibited no affect on cell viability, as assessed using an MTT assay (Fig. 1), indicating that the promising anti-obesity potential of EEZS in 3T3-L1 cells was not simply due to a cytotoxic effect.

Adipocyte differentiation is highly regulated by several transcription factors. The PPAR and C/EBP families are important in adipocyte differentiation. More specifically, the adipocyte marker transcription factors, PPAR $\gamma$ and $\mathrm{C} / \mathrm{EBP} \alpha$, have been reported to be important in differentiation and lipid storage, and in the coordinated expression of genes involved in creating or maintaining the phenotype of adipocytes $(14,15)$. Additionally, $\mathrm{C} / \mathrm{EBP} \beta$, which is considered to mediate the expression levels of PPAR $\gamma$ and $\mathrm{C} / \mathrm{EBP} \alpha$ during adipogenesis, is the first transcription factor induced following exposure of pre-adipocytes to differentiation medium and, therefore, may be involved in directing the differentiation process $(32,33)$. The present study revealed that EEZS significantly downregulated the protein expression levels of PPAR $\gamma, \mathrm{C} / \mathrm{EBP} \alpha$ and $\mathrm{C} / \mathrm{EBP} \beta$, induced by differentiation medium, in the 3T3-L1 cells (Fig. 4). Therefore, EEZS appeared to inhibit adipogenesis, which may be attributable to its ability to downregulate the expression levels of adipocyte marker proteins.
It has also been reported that activation of the ERK and PI3K/Akt pathways is necessary for adipogenesis $(18,19)$. Activation of these pathways during adipogenesis promotes differentiation by activating factors that regulate the expression levels of PPAR $\gamma$ and C/EBPs. Several previous studies have demonstrated that the activation of ERK and Akt induces differentiation by activating factors, which regulate the expression levels PPAR $\gamma$ and C/EBPs during the early-stages of adipogenesis $(14,15)$. In addition, there is increasing evidence that the inhibition of the ERK and Akt pathways in adipocyte differentiation inhibits adipogenesis $(16,34,35)$. Therefore, to further assess the effect of EEZS on the upstream signaling pathways of PPAR $\gamma$ and $C / E B P s$, the present study investigated the effects of EEZS on the expression levels of phosphorylated-ERK and Akt. As the phosphorylation of Akt is regulated by PI3K, as an upstream kinase of Akt $(36,37)$, the effects of EEZS on the levels of PI3K were also determined. The data demonstrated that the phosphorylation of ERK, PI3K and Akt were significantly activated during the early stages of adipogenesis, and the activation continued for 3 or $6 \mathrm{~h}$ following the induction of adipocyte differentiation by MDI (Figs. 5 and 6). However, EEZS significantly inhibited the phosphorylation of ERK, in a time-dependent manner. The protein expression levels of total PI3K and Akt, as with ERK, remained unchanged throughout the experiment. EEZS also attenuated the protein expression levels of phosphorylated-PI3K and Akt (Fig. 6). Although the precise molecular signaling mechanism underlying EEZS remains to be elucidated, these results suggested that EEZS inhibited the activation of the ERK and PI3K/Akt pathways at an early stage and inhibited the expression of adipogenic transcription factors by modulating the ERK- and PI3K/Akt-mediated signaling pathways during adipocyte differentiation.

In conclusion, the present study demonstrated that EEZS suppressed adipogenesis in the 3T3-L1 cells by downregulating the expression levels of PPAR $\gamma, \mathrm{C} / \mathrm{EBP} \alpha$ and $\mathrm{C} / \mathrm{EBP} \beta$, through inactivation of the ERK and PI3K/Akt signaling pathways in the early stages of adipogenesis. These findings suggested the possible use of EEZS as a therapeutic substance or as a lead in the development of therapeutic substances for the prevention and management of obesity.

\section{Acknowledgements}

This study was supported by the Blue-Bio Industry Regional Innovation Center (no. RIC08-06-07) at Dongeui University, as an RIC program under the Ministry of Trade, Industry \& Energy and Busan city.

\section{References}

1. Dorresteijn JA, Visseren FL and Spiering W: Mechanisms linking obesity to hypertension. Obes Rev 13: 17-26, 2012.

2. Franssen R, Monajemi H, Stroes ES and Kastelein JJ: Obesity and dyslipidemia. Med Clin North Am 95: 893-902, 2011.

3. Rocha VZ and Libby P: Obesity, inflammation and atherosclerosis. Nat Rev Cardiol 6: 399-409, 2009.

4. McCarthy MI: Genomics, type 2 diabetes and obesity. N Engl J Med 363: 2339-2350, 2010.

5. Speliotes EK: Genetics of common obesity and nonalcoholic fatty liver disease. Gastroenterology 136: 1492-1495, 2009.

6. Pischon N, Heng N, Bernimoulin JP, Kleber BM, Willich SN and Pischon T: Obesity, inflammation and periodontal disease. J Dent Res 86: 400-409, 2007. 
7. Lloyd CM and Saglani S: Eosinophils in the spotlight: Finding the link between obesity and asthma. Nat Med 19: 976-977, 2013.

8. Tzotzas T, Evangelou P and Kiortsis DN: Obesity, weight loss and conditional cardiovascular risk factors. Obes Rev 12: e282-e289, 2011.

9. Thompson D and Wolf AM: The medical-care cost burden of obesity. Obes Rev 2: 189-197, 2001.

10. Dalla Vecchia CF, Susin C, Rösing CK, Oppermann RV and Albandar JM: Overweight and obesity as risk indicators for periodontitis in adults. J Periodontol 76: 1721-1728, 2005.

11. Zimmet P, Alberti KG and Shaw J: Global and societal implications of the diabetes epidemic. Nature 414: 782-787, 2001.

12. Bray GA and Tartaglia LA: Medicinal strategies in the treatment of obesity. Nature 404: 672-677, 2000.

13. Tam CS, Lecoultre V and Ravussin E: Novel strategy for the use of leptin for obesity therapy. Expert Opin Biol Ther 11: 1677-1685, 2011.

14. Rosen ED: The transcriptional basis of adipocyte development. Prostaglandins Leukot Essent Fatty Acids 73: 31-34, 2005.

15. Soukas A, Socci ND, Saatkamp BD, Novelli S and Friedman JM Distinct transcriptional profiles of adipogenesis in vivo and in vitro. J Biol Chem 276: 34167-34174, 2001.

16. Prusty D, Park BH, Davis KE and Farmer SR: Activation of MEK/ERK signaling promotes adipogenesis by enhancing peroxisome proliferator-activated receptor gamma (PPARgamma) and $\mathrm{C} / \mathrm{EBPalpha}$ gene expression during the differentiation of 3T3-L1 preadipocytes. J Biol Chem 277: 46226-46232, 2002.

17. Rosen ED and MacDougald OA: Adipocyte differentiation from the inside out. Nat Rev Mol Cell Biol 7: 885-896, 2006.

18. Smith PJ, Wise LS, Berkowitz R, Wan C and Rubin CS: Insulin-like growth factor-I is an essential regulator of the differentiation of 3T3-L1 adipocytes. J Biol Chem 263: 9402-9408, 1988.

19. Bost F, Aouadi M, Caron L and Binétruy B: The role of MAPKs in adipocyte differentiation and obesity. Biochimie 87: 51-56, 2005.

20. Magun R, Burgering BM, Coffer PJ, Pardasani D, Lin Y, Chabot J and Sorisky A: Expression of a constitutively activated form of protein kinase B (c-Akt) in 3T3-L1 preadipose cells causes spontaneous differentiation. Endocrinology 137: 3590-3593, 1996.

21. Peng XD, Xu PZ, Chen ML, Hahn-Windgassen A, Skeen J, Jacobs J, Sundararajan D, Chen WS, Crawford SE, Coleman KG and Hay N: Dwarfism, impaired skin development, skeletal muscle atrophy, delayed bone development and impeded adipogenesis in mice lacking Akt1 and Akt2. Genes Dev 17: 1352-1365, 2003.

22. Jo YS, Huong DT, Bae K, Lee MK and Kim YH: Monoamine oxidase inhibitory coumarin from Zanthoxylum schinifolium. Planta Med 68: 84-85, 2002.

23. Paik SY, Koh KH, Beak SM, Paek SH and Kim JA: The essential oils from Zanthoxylum schinifolium pericarp induce apoptosis of HepG2 human hepatoma cells through increased production of reactive oxygen species. Biol Pharm Bull 28: 802-807, 2005.
24. Tsai IL, Lin WY, Teng CM, Ishikawa T, Doong SL, Huang MW, Chen YC and Chen IS: Coumarins and antiplatelet constituents from the root bark of Zanthoxylum schinifolium. Planta Med 66: 618-623, 2000.

25. Chen IS, Lin YC, Tsai IL, Teng CM, Ko FN, Ishikawa T and Ishii $\mathrm{H}$ : Coumarins and anti-platelet aggregation constituents from Zanthoxylum schinifolium. Phytochemistry 39: 1091-1097, 1995.

26. Cao LH, Lee YJ, Kang DG, Kim JS and Lee HS: Effect of Zanthoxylum schinifolium on TNF-alpha-induced vascular inflammation in human umbilical vein endothelial cells. Vascul Pharmacol 50: 200-207, 2009.

27. Li W, Sun YN, Yan XT, Yang SY, Kim EJ, Kang HK and Kim YH: Coumarins and lignans from Zanthoxylum schinifolium and their anticancer activities. J Agric Food Chem 61: 10730-10740, 2013.

28. Jun DY, Kim JS, Park HS, Han CR, Fang Z, Woo MH, Rhee IK and Kim YH: Apoptogenic activity of auraptene of Zanthoxylum schinifolium toward human acute leukemia Jurkat $\mathrm{T}$ cells is associated with ER stress-mediated caspase- 8 activation that stimulates mitochondria-dependent or -independent caspase cascade. Carcinogenesis 28: 1303-1313, 2007.

29. Kim MY, Kim DH and Do MS: B-cell-activating factor is a regulator of adipokines and a possible mediator between adipocytes and macrophages. Exp Mol Med 45: e4, 2013.

30. Rhyu J, Kim MS, You MK, Bang MA and Kim HA: Pear pomace water extract inhibits adipogenesis and induces apoptosis in 3T3-L1 adipocytes. Nutr Res Pract 8: 33-39, 2014.

31. Kopelman PG: Obesity as a medical problem. Nature 404: 635-643, 2000

32. Ntambi JM and Young-Cheul K: Adipocyte differentiation and gene expression. J Nutr 130: 3122S-3126S, 2000.

33. Tong Q and Hotamisligil GS: Molecular mechanisms of adipocyte differentiation. Rev Endocr Metab Disord 2: 349-355, 2001.

34. Cornelius P, MacDougald OA and Lane MD: Regulation of adipocyte development. Annu Rev Nutr 14: 99-129, 1994.

35. Kohn AD, Summers SA, Birnbaum MJ and Roth RA: Expression of a constitutively active Akt Ser/Thr kinase in 3T3-L1 adipocytes stimulates glucose uptake and glucose transporter 4 translocation. J Biol Chem 271: 31372-31378, 1996.

36. Uto-Kondo H, Ohmori R, Kiyose C, Kishimoto Y, Saito H, Igarashi $\mathrm{O}$ and Kondo K: Tocotrienol suppresses adipocyte differentiation and Akt phosphorylation in 3T3-L1 preadipocytes. J Nutr 139: 51-57, 2009.

37. Zhang HH, Huang J, Düvel K, Boback B, Wu S, Squillace RM, Wu CL and Manning BD: Insulin stimulates adipogenesis through the Akt-TSC2-mTORC1 pathway. PLoS One 4: e6189, 2009. 